NBER WORKING PAPER SERIES

\title{
CORN PRODUCTION SHOCKS IN 2012 AND BEYOND: IMPLICATIONS FOR FOOD PRICE VOLATILITY
}

\author{
Steven T. Berry \\ Michael J. Roberts \\ Wolfram Schlenker \\ Working Paper 18659 \\ http://www.nber.org/papers/w18659
NATIONAL BUREAU OF ECONOMIC RESEARCH
1050 Massachusetts Avenue
Cambridge, MA 02138 \\ December 2012
}

Financial support from National Science Foundation Grant SES-0962559 is thankfully acknowledged. The views expressed herein are those of the authors and do not necessarily reflect the views of the National Bureau of Economic Research.

At least one co-author has disclosed a financial relationship of potential relevance for this research. Further information is available online at http://www.nber.org/papers/w18659.ack

NBER working papers are circulated for discussion and comment purposes. They have not been peerreviewed or been subject to the review by the NBER Board of Directors that accompanies official NBER publications.

(C) 2012 by Steven T. Berry, Michael J. Roberts, and Wolfram Schlenker. All rights reserved. Short sections of text, not to exceed two paragraphs, may be quoted without explicit permission provided that full credit, including $(\mathcal{C}$ notice, is given to the source. 
Corn Production Shocks in 2012 and Beyond: Implications for Food Price Volatility

Steven T. Berry, Michael J. Roberts, and Wolfram Schlenker

NBER Working Paper No. 18659

December 2012

JEL No. Q11,Q5

\begin{abstract}
$\underline{\text { ABSTRACT }}$
Corn prices increased sharply in the summer of 2012 due to expected production shortfalls in the United States, which produces roughly $40 \%$ of the world's corn. A heat wave in July adversely affected corn production. We extend earlier statistical models of county-level corn yields in the Eastern United States by allowing the effect of various weather measures to vary in a flexible manner over the growing season: Extreme heat is especially harmful around a third into the growing season. This is the time when the 2012 heat wave hit the Corn Belt. Our model predicts 2012 corn yields will be $23 \%$ below trend. While extreme heat was significantly above normal, climate change scenarios suggest that the 2012 outcomes will soon be the new normal.
\end{abstract}

\author{
Steven T. Berry \\ Yale University Department of Economics \\ Box 208264 \\ 37 Hillhouse Avenue \\ New Haven, CT 06520-8264 \\ and NBER \\ steven.berry@yale.edu \\ Michael J. Roberts \\ Department of Economics \\ University of Hawaii at Manoa \\ Saunders Hall 542 \\ 2424 Maile Way \\ Honolulu, HI 96822 \\ mjrobert@hawaii.edu
}

Wolfram Schlenker

Agricultural and Resource Economics

University of California at Berkeley

329 Giannini Hall

Berkeley, CA 94720

and NBER

schlenker@berkeley.edu 
Historically, $25 \%$ of an average year's global corn production is held in inventories to buffer weather shocks and allow for a smooth consumption between years. As inventory levels are drawn down, prices increase, thereby giving farmers an incentive to increase production in the following years to refill depleted inventory levels.

While individual countries might face significant production shocks, these idiosyncratic shocks average out over the globe. Global corn production shocks (deviations from a trend) ranged from $-13 \%$ to $+7 \%$ in 1961-2010, with a standard deviation of $4 \%$ (Roberts \& Schlenker Forthcoming). International trade smoothens production shocks between countries unless these countries institute export bans.

There are, however, certain exceptions to this rule. The production of some crops is highly spatially correlated and subject to the same common weather shocks. A prime example is corn production in the United States, which is grown in the Midwest. Since the US produces roughly $40 \%$ of the world's corn, any impact to US production has the potential to significantly affect global production and global price levels.

Current and future corn price volatility depends directly on production shocks. One of the main driver of production shocks are weather fluctuations. An accurate model that translates weather fluctuations into production fluctuations is hence a crucial first step in examining food price volatility.

In this paper we extend earlier work on the effects of weather on corn production (Schlenker \& Roberts 2009). We previously allowed for a highly non-linear effect of weather on corn yields, but assumed the effect of various temperatures to be constant throughout the growing season that we fixed to March-August. The main innovations of this paper are: First, we allow the effect of various weather measures to evolve over the growing season. Second, we no longer keep the growing season fixed to March-August, but rather use annual state-level data on plating and harvest dates to capture weather measures over the actual growing season. Third, we predict yields for 2012 using the traditional as well as the new model. Since the 2012 heat wave happened during the part of the growing season when it is most harmful, the new model predicts larger production shortfalls. Fourth, we contrast 2012 to what is expected under climate change.

\section{$1 \quad$ Model}

We start by estimating a baseline model of yields that assumes a fixed growing season (March-August) and a constant effect of weather variables over the growing season. This 
baseline replicates a specification from earlier research (Schlenker \& Roberts 2009). In a second step, following Ortiz-Bobea \& Just (Forthcoming), we consider models that account for planting date and temperature effects that vary over the growing season.

\section{$1.1 \quad$ Baseline Model 1}

The baseline model relates $\log$ yield $y_{i t}$ in county $i$ and year $t$ to four weather variables:

$$
y_{i t}=\beta_{1} m_{i t}+\beta_{2} h_{i t}+\beta_{3} p_{i t}+\beta_{4} p_{i t}^{2}+c_{i}+f_{s}(t)+\epsilon_{i t}
$$

where $m_{i t}$ is growing degree days between 10 and $29^{\circ} \mathrm{C}$, accounts the beneficial effects of moderate temperatures, $h_{i t}$ are degree days above $29^{\circ} \mathrm{C}$ that capture the damaging effect of extreme heat, and $p_{i t}$ and $p_{i t}^{2}$ are season-total precipitation and its square. ${ }^{1}$ County fixed effects $c_{i}$ account for baseline differences between counties and state-specific time trends $f_{s}$ account for technological progress as average yields have been trending upward over time. Errors are clustered at the state level to adjust for spatial correlation.

The data underlying these regression is constructed using daily fine-scaled weather measures on a 2.5x2.5 mile grid for the contiguous United States. We follow the same algorithm of Schlenker \& Roberts (2009), but update the data until November 30, 2012. We only use counties east of the 100 degree meridian (except Florida) in the regression, because the response function might be different for highly irrigated area. The data set spans the years 1950-2012.

\subsection{Model 2: Time-Varying Parameters}

Model 2 allows the effect of weather variables to vary over the growing season. Ortiz-Bobea \& Just (Forthcoming) extend our earlier work by separating the growing season into three subintervals, and then estimate separate (constant) coefficient for each of the subintervals. This paper allows the effect of weather variables to vary continuously over time. To make locations comparable, we use yearly data on planting and harvesting dates and normalize

\footnotetext{
${ }^{1}$ Growing degree days are based on cumulative heat exposure above a threshold temperature, which is sometimes also truncated by an upper bound. Degree days $10-29^{\circ} \mathrm{C}$ count all temperatures below $10 \mathrm{C}$ as zero, temperatures between $10^{\circ} \mathrm{C}$ and $29^{\circ} \mathrm{C}$ as the difference between the observed temperature and $10^{\circ} \mathrm{C}$, and temperatures at or above $29^{\circ} \mathrm{C}$ as 19 . For example, twenty-four hours of exposure to a temperature of $11^{\circ} \mathrm{C}$ counts as one growing degree day while twenty-four hours of exposure to a temperature of $12^{\circ} \mathrm{C}$ counts as 2 degree days, and so on. In our weather data, we incorporate the entire distribution of temperatures between the daily minimum and maximum, thereby counting fractions of a day (see the data section 2 below). Degree days above $29^{\circ} \mathrm{C}$ put the lower bound at $29^{\circ} \mathrm{C}$ and have no upper bound.
} 
the season to have length 1 . A value of 0.5 stands for the day that occurred in the middle of the growing season.

In a first step we only allow the coefficient $\beta_{2}$ that measures the effect of extreme heat to vary over the growing season. The reason is that extreme heat has consistently been found to have the largest influence on year-to-year variability of crop yields. There is agronomic evidence that heat matters especially during the flowering period, and the effect of this weather measures might hence evolve over time. Model 2 is defined as:

$$
y_{i t}=\beta_{1} m_{i t}+g_{2}\left(h_{0 i t}, \ldots, h_{D_{i t} i t}\right)+\beta_{3} p_{i t}+\beta_{4} p_{i t}^{2}+c_{i}+f_{s}(t)+\epsilon_{i t}
$$

In the baseline model we summed daily degree days above $29^{\circ} \mathrm{C}$ over all days of the fixed growing season $\sum_{d=\text { March } 1}^{\text {August } 31} h_{d i t}$, while $g_{2}()$ now allows the effect of $h_{d i t}$ to vary over the growing season. Note that we also no longer fix the growing season to March 1st-August 31st, but allow it to vary year to year. Different places might have different growing season lengths, and there is year-to-year variation in planting and harvesting dates at a given location. We define a growing season to last from plating (time 0) to harvest (time 1).

We construct a restricted cubic spline with $k$ knots over the growing season, which will result in $k-1$ spline variables $s_{j}()$. We consider models with between 3 and 7 knots, with the knots placed at standard fractions of the growing season. ${ }^{2}$ We normalize the growing season to length one, so the "weighted" sum of daily degree days above $29^{\circ} \mathrm{C}\left(h_{d i t}\right)$ over all days $d$ of the growing season $d=0,1,2 \ldots D_{i t}$ in county $i$ in year $t$ depends on the phase of the growing season $x_{d i t}=\frac{d-1}{D_{i t}-1}$ that varies between 0 and 1 .

$$
g_{2}\left(h_{i t}\right)=\sum_{d=0}^{D_{i t}} h_{d i t} \underbrace{\sum_{j=1}^{k} s_{j}\left(x_{d i t}\right)}_{\text {weight(time) }}=\sum_{j=1}^{k-1} \underbrace{\sum_{d=1}^{D_{i t}} s_{j}\left(x_{d i t}\right) h_{d i t}}_{H_{j i t}}=\sum_{j=1}^{k-1} \beta_{2 j} H_{j i t}
$$

The second equality simply exchanges the order of summation. We are ultimately left with $j=1 \ldots k-1$ variables $H_{j i t}$, which are the sum of daily degree days above $29^{\circ} \mathrm{C}\left(h_{d i t}\right)$ weighted by the value of the spline function $s_{j}\left(x_{d i t}\right)$ for each day (phase) of the growing season.

We also estimate an extended model 2 that allows the effect of other weather variables

\footnotetext{
${ }^{2}$ Spline knots locations are as follows: $k=3$ indicates three knots set at $0.1,0.5$, and 0.9 fractions of the total growing season; $k=4$ indicates knots set at $0.05,0.35,0.65$, and $0.95 ; k=5$ spline knots set at 0.02 , $0.26,0.5,0.74$, and $0.98 ; k=6$, knots are set at $0.02,0.212,0.404,0.596,0.788$, and $0.98 ; k=7$ knots are set at $0.02,0.18,0.34,0.5,0.66,0.82$, and 0.98 .
} 
to vary over the growing season. It includes a fifth variable, which is the interaction of daily degree days above $29^{\circ} \mathrm{C}$ and daily precipitation

$$
\begin{aligned}
y_{i t}= & g_{1}\left(m_{0 i t}, \ldots, m_{D_{i t} i t}\right)+g_{2}\left(h_{0 i t}, \ldots, h_{D_{i t} i t}\right)+g_{3}\left(p_{0 i t}, \ldots, p_{D_{i t} i t}\right)+g_{4}\left(p_{0 i t}^{2}, \ldots, p_{D_{i t} i t}^{2}\right) \\
& +g_{5}\left(h_{0 i t} \times p_{0 i t}, \ldots, h_{D_{i t} i t} \times p_{D_{i t} i t}\right)+c_{i}+f_{s}(t)+\epsilon_{i t}
\end{aligned}
$$

Note that the effect of precipitation is modeled differently. Earlier models uses season-

total precipitation and season-total precipitation squared. The extended model 2 uses daily precipitation as well as daily precipitation squared, and allows the effects of these variables to vary over the growing season.

\section{Data}

We pair data on annual county-level corn yields with fine scaled-weather measures that were constructed on a 2.5x2.5 mile grid for the entire United States. We follow the same algorithm of Schlenker \& Roberts (2009), but update the data until November 30, 2012. These data give daily minimum and maximum temperature, dew point, as well as precipitation for each grid cell. Degree days above a threshold $b$ are calculated by fitting a sine-curve between the daily minimum and maximum temperature in each cell and integrating over the difference between the temperature curve and the threshold (Snyder 1985). Daily weather measures for all grids in a county are weighted averages, where the weights are the cropland area in each grid cell that were obtained from a satellite scan. This gives daily weather measures for each county.

In the baseline model, we sum degree days over all days of the growing season, which was fixed to March 1st-August 31st for all counties and years. These variables were calculated using all counties east of the 100 degree meridian (except Florida). The second row of Table 1 displays the fraction of the US growing area and production that falls in these countries for the three most recent years 2009-2011. With approximately 90\% of the growing area and total production, these counties account for the largest share of US corn production. Given this large coverage, average yields from these counties closely match overall US yields as shown in the last two columns of the table. 


\subsection{Weather Anomalies for a Fixed Growing Season (Model 1)}

Weather measures for counties east of the 100 degree meridian (except Florida) that grow corn are displayed on the maps in Figure 1. The top graph shows 2012 anomalies of seasontotal degree days above $29^{\circ} \mathrm{C}$ for a fixed growing season of March-August, i.e., the difference between 2012 and the average from 1950-2011. The bottom graph shows the 2012 anomalies for season-total precipitation. There is a lot of heterogeneity across counties, with some counties experiencing above normal conditions, while others experience below-normal conditions for both weather variables. The corn belt was hotter and drier than usual, while Southern counties had a cooler and wetter than average year. Note the variation in extreme heat: the production-weighted average exposure to degree days above $29^{\circ} \mathrm{C}$ is 33 among all eastern counties in 1950-2011. Some highly productive counties in the Corn Belt experienced up to 105 extra degree days above $29^{\circ} \mathrm{C}$. As we show below, each degree days above $29^{\circ} \mathrm{C}$ reduces $\log$ yields by 0.006 , so the effect of an extra 100 degree days above $29^{\circ} \mathrm{C}$ is a decrease of $60 \log$ points.

Since bad weather in highly productive areas can cause a loss that is not compensated by better-than average weather in less productive areas, we summarize weather outcomes by constructing the production-weighted average of all eastern counties. Production weights are the product of actual area (which is known at the beginning of the season) and predicted yields according to a trend. ${ }^{3}$ Figure 2 shows the evolution of the cumulative season total degree days measures over the 184 days of the growing season, ranging from March 1st (day 0) to August 31st (day 183). We average cumulative season totals up to a given day of the growing season. Historic exposures for the years 1950-2011 are shown as grey dashed lines, while the outcome for 2012 is shown as a thick solid red line.

The top panel of Figure2 shows degree days $10-29^{\circ} \mathrm{C}$. Degree days above $10-29^{\circ} \mathrm{C}$ start to increase earlier than usual in 2012 since the US had a warm spring. The beneficial side effect of a warmer spring is that it allows for earlier planting. The bottom graph of Figure 2 shows degree days above $29^{\circ} \mathrm{C}$. July and August are traditionally the months where temperatures climb above $29^{\circ} \mathrm{C}$ most frequently and degree days above $29^{\circ} \mathrm{C}$ increase most rapidly. July 2012 was exceptionally hot by historic standards. At the beginning of July, the measures was slightly above normal, but by the end of July, it had superseded the hottest year among the 1950-2011 historic baseline, which was 1988. Note that 1988 had a hotter August than 2012 , and as a result the season total degree days above $29^{\circ} \mathrm{C}$ was highest in 1988 , followed by 2012 .

\footnotetext{
${ }^{3}$ We fit a restricted cubic spline with three knots to the yield history of each county.
} 
The top graph of Figure 3 displays the cumulative season-total precipitation. Precipitation was below normal in 2012, and the only year with drier condition in the 1950-2011 historic baseline is again 1988. Note, however, that the relative deviation from the mean is much lower for precipitation than for degree days above $29^{\circ} \mathrm{C}$. Finally, the bottom graph of Figure 3 shows cumulative vapor pressure deficit, which is the difference between how much water the air can hold when it is saturated and how much water is currently in the air. This measure is used in agronomic crop models and has also been shown to predict yields in a statistical models (Roberts, Schlenker \& Eyer Forthcoming). Similar to precipitation, this measures indicates that crops were adversely affected (a higher than usual deficit is bad for crops), yet the relative deviation from the mean was less than for degree days above $29^{\circ} \mathrm{C}$.

\subsection{Planting and Harvest Dates (Model 2)}

The second model relaxes two assumptions: first, we no longer fix the growing season to March-August, but instead used data from the National Agricultural Statistics Service (NASS) on planting and harvesting dates. NASS reports on a weekly level what fraction of the corn area in major corn-producing states was planted and harvested. We define the beginning of the growing season as the Monday of the week by the end of which at least $50 \%$ of the corn area in a state had been planted. Similarly, the end of the growing season is the last day of a week when at least $50 \%$ of the growing area had been harvested in a state.

The average planting date for each county is shown in the top graph of Figure 4. Southern places tend to plant earlier, as they are not limited by the probability of late freezes. Northern places also have a larger intra-year cycle in solar radiation, which is an important component of crop growth that limits farmers from shifting the planting date too much forward. We do not fix the growing season in each place but allow it to vary between years according to annual NASS reports. In case only the planting date is available for a state, but not the harvest date, we approximate the harvest date by adding the average growing season length to the reported planting date. By the same token, if the harvest date is reported but the planting date is missing, we approximate the latter by subtracting the average growing season length from the harvest date. The harvest date in 2012 are approximated by adding the average growing season length to the observed planting dates. ${ }^{4}$

Southern places have a longer growing season as shown in the bottom graph of Figure 4. As mentioned above, we make the different growing seasons comparable by rescaling them such that the first day is 0 , while the last day is 1 . After fitting spline polynomials over the

\footnotetext{
${ }^{4}$ Actual harvest dates were not available at the time of writing.
} 
season, we aggregate the variables to an annual level.

The number of yearly observations for which we have yield and planting data in a county county is shown in Figure 5. The first year in which data on planting and harvesting dates is available is 1979, but many states started to report planting dates at a later time. Counties

in the Eastern United States (except Florida) that report planting and/or harvest dates are summarized in the third row of Table 1. States that report planting dates account for $85 \%$ of the corn growing area and $87 \%$ of the US corn production in the most recent three years (2009-2011).

The second innovation of model 2 is to relax the assumption that the effect of some, and eventually all, weather variables are constant over the growing season. As outlined in Section 1, we interact daily measures of the weather variables with spline polynomials. This allows the effect to differ over the growing season in a flexible way.

Figure 6 displays the average daily exposure over the growing season for four weather variables: degree days $10-29^{\circ} \mathrm{C}$, degree days above $29^{\circ} \mathrm{C}$, precipitation, and vapor pressure deficit. We use either restricted cubic splines with 4, 5, 6, or 7 knots. The results seem fairly stable as long as we include at least 5 knots.

\section{Empirical Results}

We start by replicating the results for a fixed growing season (March-August) that assume constant marginal effects of the weather variables before relaxing both assumptions.

\subsection{Baseline Model 1}

Results for a panel analysis for eastern counties (except Florida) for the years 1950-2011 is given in Table 2. All columns use the same set of observations, but vary the set of time controls that are used to capture overall trends in yields. Columns (a), (b), and (c) use statespecific restricted cubic splines with 3, 4, and 5 knots, respectively. On top of that, columns (2a)-(2c) also include year fixed effects to capture overall shocks, like changes in global food prices or technological breakthroughs. The results are very stable across specifications. Moderate heat (degree days $10-29^{\circ} \mathrm{C}$ ) is beneficial, while extreme heat (degree days above $29^{\circ} \mathrm{C}$ ) is highly damaging. Note that 2000 degree days $10-29^{\circ} \mathrm{C}$ increase expected yields by as much as 100 degree days above $29^{\circ} \mathrm{C}$ decrease them. Moreover, a coefficient of -0.6 on degree days above $29^{\circ} \mathrm{C}$ implies that the 100 additional degree days are lowering expected yields by $60 \log$ points. Recall that several counties in the corn belt experienced heat anomalies 
of that magnitude in 2012 (see Figure 1). Finally, precipitation and precipitation squared suggest that the relationship is hill-shaped (both too little and too much rain are harmful). The optimum is around $0.63 \mathrm{~m}$, or 25inches, which matches closely the estimate of optimal rainfall from agronomic studies.

The effect of the 2012 weather outcomes on expected yields are shown in Figure 7. The top graph depicts predicted deviations from the time trend in log points (using the specification from column (1a) in Table 2). There is significant heterogeneity: some counties are predicted to be as much as $60 \%$ below normal, while others experience yields up to $32 \%$ above normal. Unfortunately, yield declines are concentrated in the more productive areas. The bottom graph of the figure does not show relative impacts, but predicted total impacts. We set the harvest area to the average of the last three years (2009-2011) and multiply it with the predicted production shortfall per area. While Northern and Southern areas experience small absolute increases, counties of the corn belt are predicted to experience large declines. The overall impact for our sample is a $15 \%$ production shortfall.

\subsection{Model 2: Time-Varying Growing Season and Parameters}

When we allow the effect of weather variables to vary over the growing season, we have to restrict the data set to a smaller set of counties for which annual planting and harvest dates are available. Column (1) of Table 3 therefore still forces the effect of each weather variable to be constant over the growing season, but runs the regression on the subset of counties for which planting dates are available and uses the weather measures when they are averaged over the actual growing season (instead of March-August). The coefficient on the two degree days variables remain rather unchanged. The precipitation variables are different: we previously measured growing season total precipitation and its square. Since we are now interested how the effect varies over the growing season, we use daily precipitation and daily precipitation squared, which are then aggregated over the season. Panel $\mathrm{C}$ summarizes the predicted decrease in total production from the observed 2012 weather outcomes, which is $19 \%$.

Column (2a)-(2d) allow the effect of extreme heat, which had the largest effect on yearto-year yield variability to vary over the growing season. The columns use $k=4,5,6$, or 7 spline knots, respectively. The coefficient estimates on the $k-1$ spline polynomials are difficult to interpret, and we hence plot them over the growing season in Figure 8. There is considerable heterogeneity over the growing season: the most damaging effects occur during phase $0.3-0.4$ of the growing season irrespective of how many spline knots we use. The 
behavior at the boundaries (close to 0 and 1) should be interpreted with caution, as there is little mass at these endpoints as shown in Figure 6. Panel $\mathrm{B}$ of Table 3 tests whether the time-varying portion (not the constant effect of degree days above $29^{\circ} \mathrm{C}$ ) are statistically significant, which is always the case. Predicted damages of the 2012 heat wave increase to $23-25 \%$ in Panel C, which is not surprising as most of the excessive heat happened in July, which is in the 0.3-0.4 window when extreme heat is most damaging. The spatial distribution of the predicted impacts for the specification in column (2b) is given in the top graph of Figure 9. ${ }^{5}$ Note that broadly comparable spatial pattern to the results we got when we fixed the growing season to March-August and forced the weather variables to have the same impact for all days of the growing season in Figure 7, but the magnitude of the impacts is larger.

A lot of media coverage focused on the concurrence of extremely hot temperatures and drought conditions. Table 4 therefore also includes an interaction term between daily degree days above $29^{\circ} \mathrm{C}$ and daily precipitation levels. The interaction is not significant in column (2), and the inclusion has almost no effect on the predicted impact of the 2012 weather outcomes in Panel C. Panels (3) through (6) consecutively relax the assumption that various weather variables are constant over the growing season (we use state-specific restricted cubic splines with 3 spline knots to capture time trends and restricted cubic splines with 5 knots tocapture seasonality components of the effects of weather variables for all specifications). While the time-variant portions of all weather variables are significant as shown in panel B (p-values are generally les than 0.05), the predicted weather impacts for 2012 in Panel C are comparable to a model where we only allow the effect of degree days above $29^{\circ} \mathrm{C}$ to vary over the growing season. The spatial distribution of impacts under the most flexible model (column 6) is shown in the bottom graph of Figure 9. The pattern is remarkably similar to the top graph that only allows the effect of degree days above $29^{\circ} \mathrm{C}$ to vary over the growing season.

\section{Discussion}

The 2012 heat wave resulted in significant production shortfalls. A baseline model that holds the growing season as well as the effect of the weather variables over the growing season constant gives predicted declines of $15 \%$. If we instead average the weather measures

\footnotetext{
${ }^{5}$ Since the state-specific planting dates are only available for some years starting 1979, weather anomalies are calculated as the difference to the observed weather average in our estimation sample.
} 
over the actual growing season, the impacts increase to $19 \%$, and if we allow the effect of extreme heat to vary over the growing season, the predicted damages increase further in magnitude to $23 \%$ as the heat wave hit when it is most damaging.

For comparison, a comparable model to our baseline model in Schlenker \& Roberts (2009) predicted decreases of slightly more than $20 \%$ under the Hadley III climate change model by mid-century (2020-2049). The predicted impacts from 2012 are hence predicted to become more frequent pretty soon if the climate forecasts turn out to be accurate.

Hansen, Sato \& Ruedy (2012) look at the frequency of extreme temperatures around the world and argue that it is predicted to increase significantly with climate change. The paper finds that the United States is one of the few areas that has been "lucky" so far, in the sense that it has not seen a significant increase in observed extremes. The current year might soon be the new normal.

\section{Conclusions}

We model the impact of the 2012 heat wave / drought with two models. A baseline model keeps the growing season as well the effect of various weather measures over the growing season constant. In a new extension, we then obtain the actual growing season on a state level and allow the effect of weather to vary over the growing season. We find that the time-varying components are highly statistically significant.

The baseline model predicts overall production declines in our sample of $15 \%$. While some areas are severely hit, others actually have above-normal yields. Once we use the actual growing season (instead of the artificially fixed one), the production decline goes up in magnitude to $19 \%$. If the effect of extreme heat is allowed to vary over the growing season, the predicted damage increases further to $23 \%$ as the heat wave hit during a time when it is most damaging. Production shortfalls of $23 \%$ in an area that accounts for $40 \%$ of global production will have strong effects on prices. Recall that historic global corn production shocks (deviations from a trend) ranged from $-13 \%$ to $+7 \%$ in $1961-2010$.

If climate forecasts turn out to accurate, we will experience increased variability in degree days above $29^{\circ} \mathrm{C}$ even if the variance of temperatures remains constant. The reason behind this behavior is that degree days above $29^{\circ} \mathrm{C}$ are a truncated temperature variable. An upward shift in the mean of the variable that leaves the variance constant will increase year-to-year variability of degree days above $29^{\circ} \mathrm{C}$ as the bound of $29^{\circ} \mathrm{C}$ binds less frequently. Temperature fluctuations below $29^{\circ} \mathrm{C}$ have no effect on degree days above $29^{\circ} \mathrm{C}$, while tem- 
perature fluctuations above the threshold do. An upward shift in temperatures hence shifts more mass of the probability distribution to a region where it translates into fluctuations of degree days. Climate change has the potential to not only decrease average production, but also to make it more volatile. As a response, food price volatility will likely increase, even though some of the increased volatility will be buffered through higher storage levels.

\section{References}

Hansen, James, Makiko Sato, and Reto Ruedy. 2012. "Perceptions of Climate Change: The New Climate Dice." WorkingPaper.

Ortiz-Bobea, Ariel, and Richard E. Just. Forthcoming. "Modeing the Structure of Adaptation in Climate Change Impact Assessment." American Journal of Agricultural Economics.

Roberts, Michael J., and Wolfram Schlenker. Forthcoming. "Identifying Supply and Demand Elasticities of Agricultural Commodities: Implications for the US Ethanol Mandate." American Economic Review.

Roberts, Michael J., Wolfram Schlenker, and Jonathan Eyer. Forthcoming. "Agronomic Weather Measures in Econometric Models of Crop Yield with Implications for Climate Change." American Journal of Agricultural Economics.

Schlenker, Wolfram, and Michael J. Roberts. 2009. "Nonlinear Temperature Effects Indicate Severe Damages to U.S. Crop Yields under Climate Change." Proceedings of the National Academy of Sciences of the United States, 106(37): 15594-15598.

Snyder, R. L. 1985. "Hand Calculating Degree Days." Agricultural and Forest Meterology, 35(1-4): 353-358. 
Figure 1: Spatial Distribution of Degree Days Above 29C and Precipitation in 2012
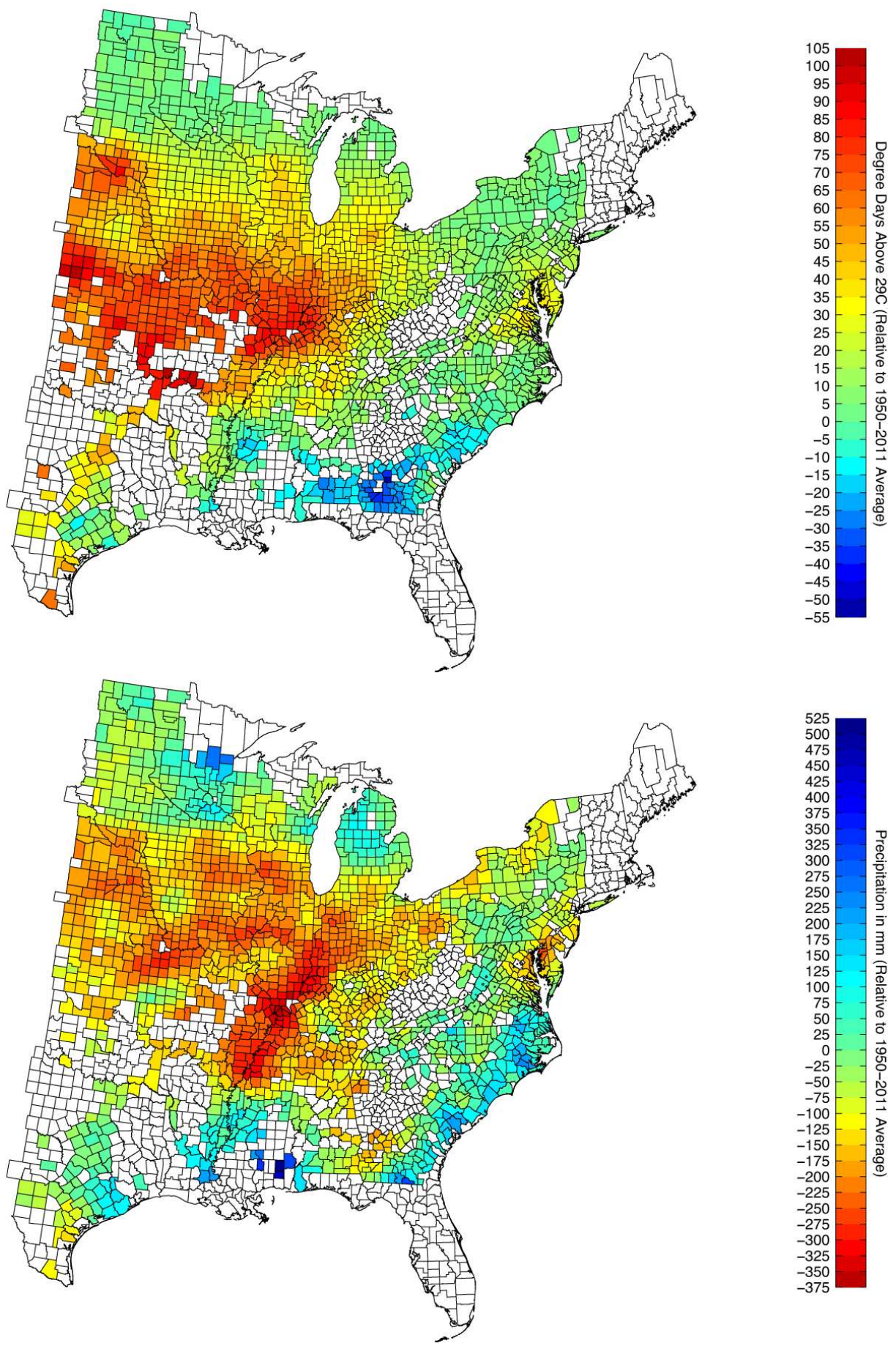

Notes: Spatial distribution of weather anomalies over the fixed 2012 growing season (March - August). Top panel shows degree days above $29^{\circ} \mathrm{C}$, while the bottom panel shows precipitation totals. 
Figure 2: Degree Days $10-29^{\circ} \mathrm{C}$ and Degree Days above $29^{\circ} \mathrm{C}$ in 2012 Relative to $1950-2011$
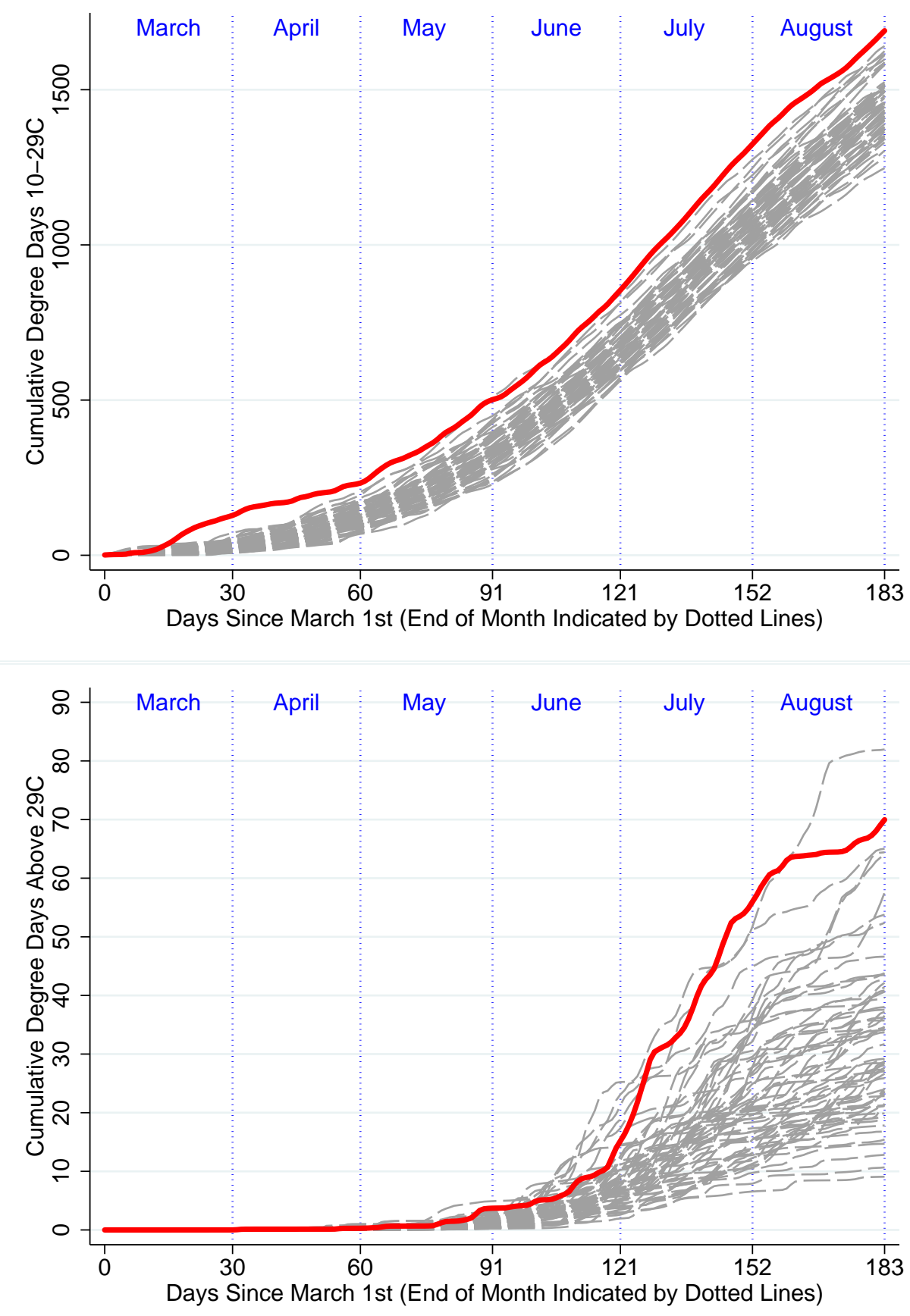

Notes: Panels show cumulative total of degree days $10-29^{\circ} \mathrm{C}$ and cumulative total of degree days above $29^{\circ} \mathrm{C}$ for the Eastern United States except Florida. Weather measures are the weighted average of all counties east of the 100 degree meridian excluding Florida, where the weights are predicted yields along a trend line (restricted cubic spline with 3 knots) times the actual growing area. Cumulative totals for the years 1950-2011 are added as thin dashed lines, while 2012 is shown as a thick solid line. 
Figure 3: Precipitation and Vapor Pressure Deficit in 2012 Relative to 1950-2011
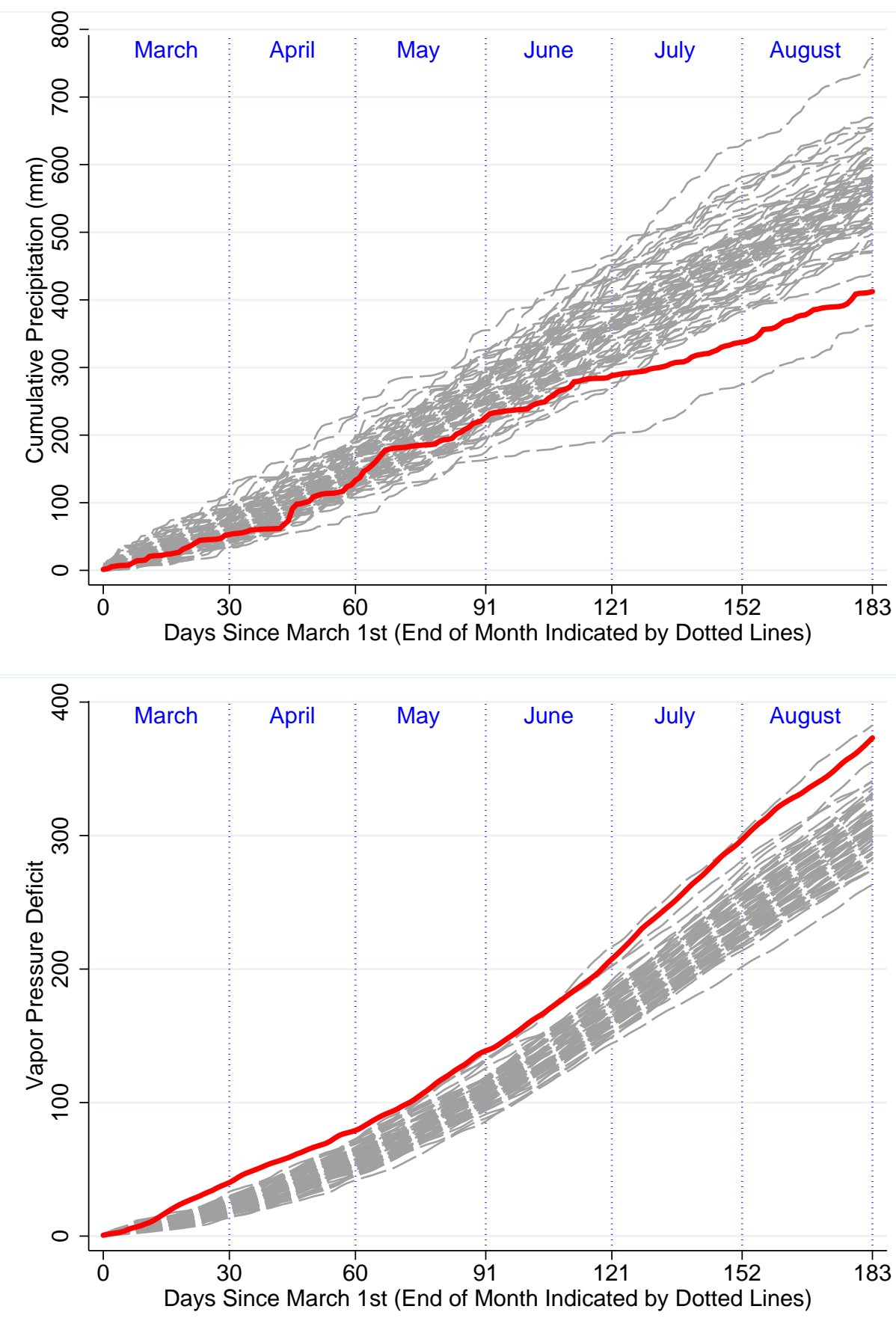

Notes: Panels show precipitation and vapor pressure deficit for Eastern United States except Florida. Weather measures are the weighted average of all counties east of the 100 degree meridian excluding Florida, where the weights are predicted yields along a trend line (restricted cubic spline with 3 knots) times the actual growing area. Cumulative totals for the years 1950-2011 are added as thin dashed lines, while 2012 is shown as a thick solid line. 
Figure 4: Average Planting Date and Growing Season Length (1979-2011)
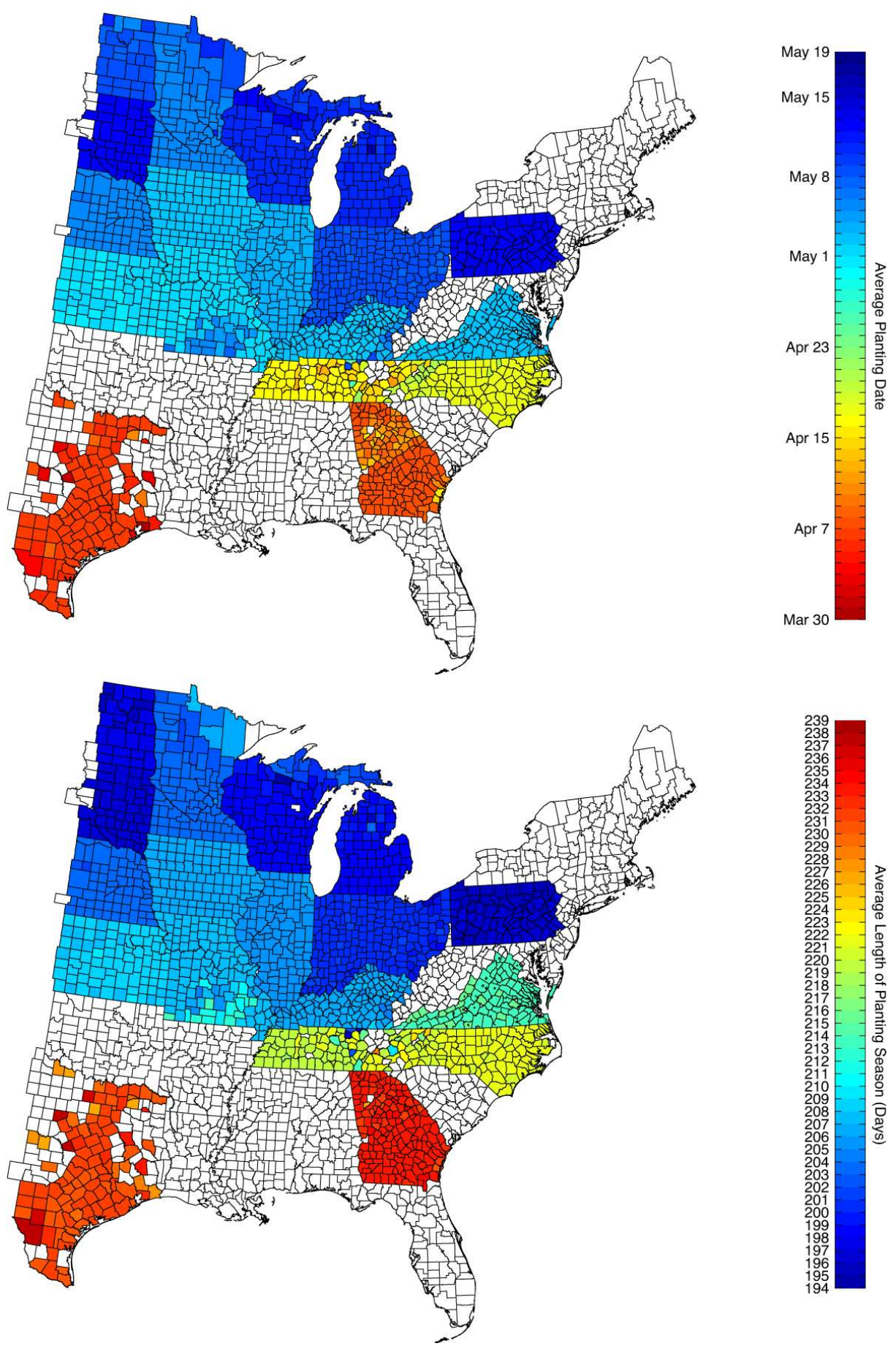

Notes: Top graph shows average planting date in 1979-2010, while bottom graph shows average growing season length. Both planting dates and growing season length are reported annually for each state. Counties within each state might have different values because they grew corn in different years. 
Figure 5: Counties with Yearly State-level Data on Planting Dates (1979-2011)

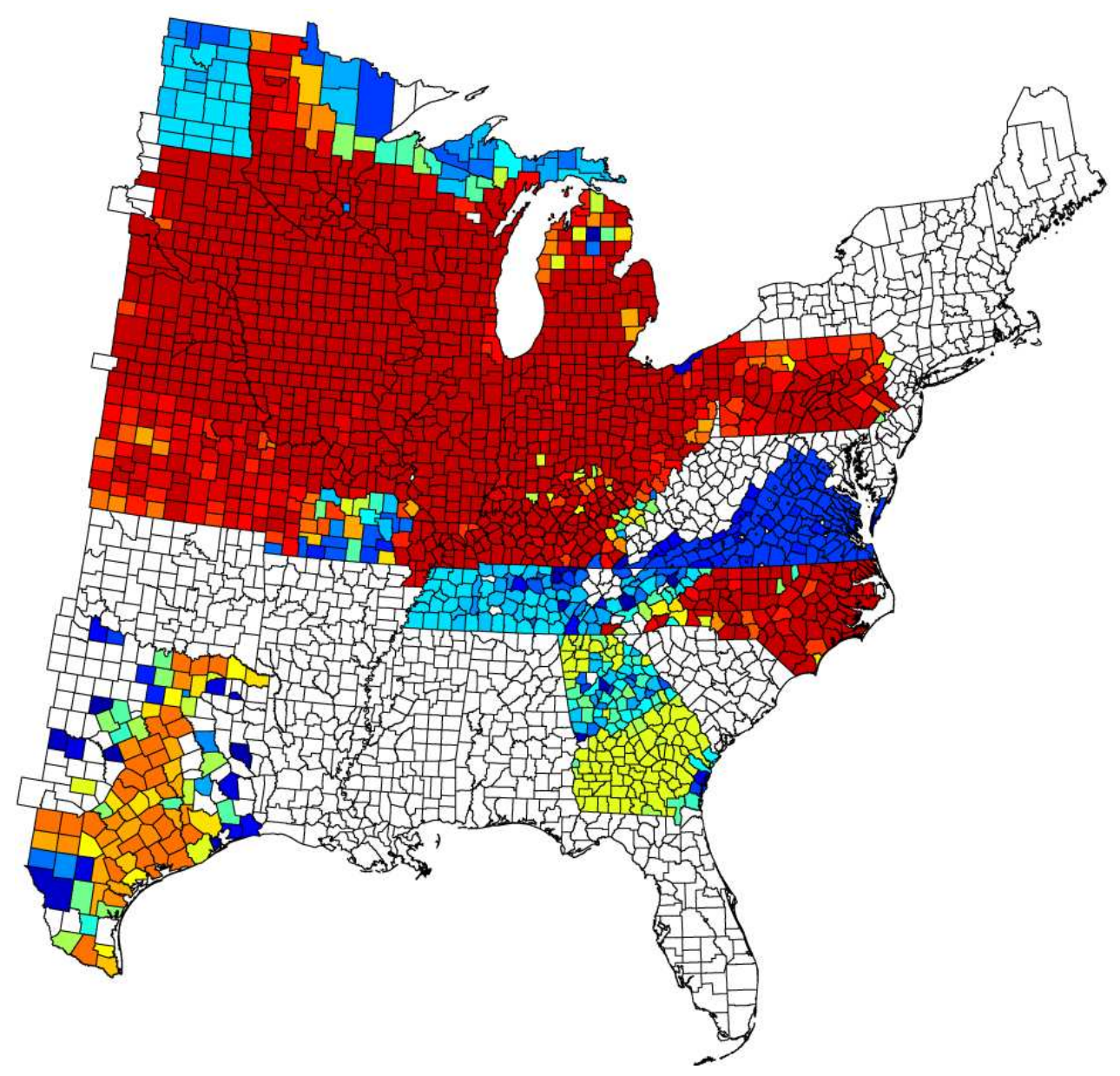

Notes: Figure displays counties for which annual planting and/or harvesting dates as well as yields were reported. Counties are color-coded by the number of yearly observations that are available for 1979-2011. Planting and harvest dates are reported on a state-level, while yields are reported for each county. The number of observations can differ within a state because yields are not reported for all counties in a state. 
Figure 6: Exposure to Various Weather Variables over the Growing Season
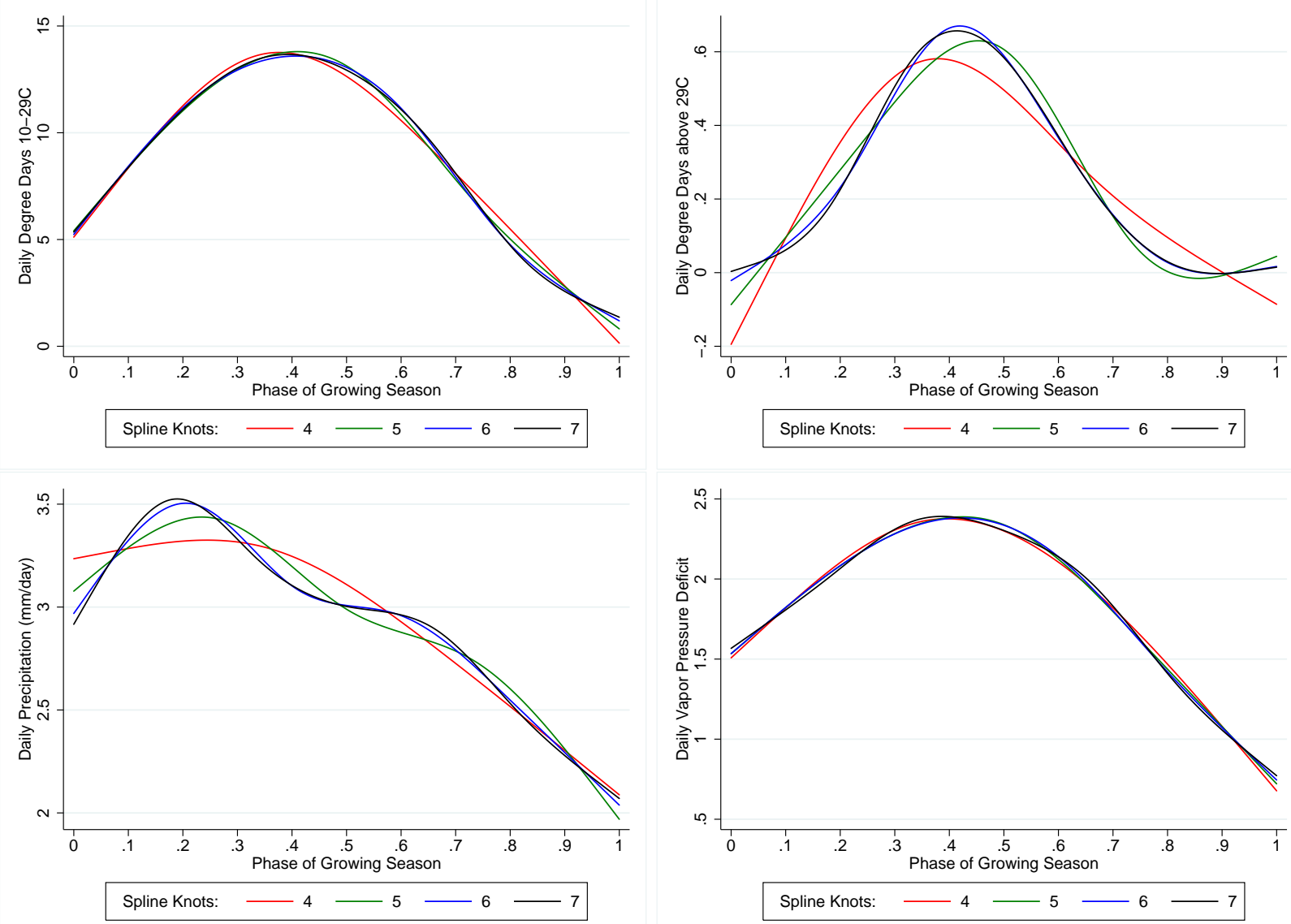

Notes: Panels show the average exposure to various weather measures over the growing season. We use yearand-state specific estimates of the National Agricultural Statistical Service (NASS) to define the growing season: The week in which the planted area exceeds $50 \%$ is the start (x-value of 0 ) and the week that the harvested area exceeds $50 \%$ is the end (x-value of 1 ). Daily values are smoothed using restricted cubic splines with $4,5,6$, or 7 knots. 
Figure 7: Predicted Yields and Production in 2012
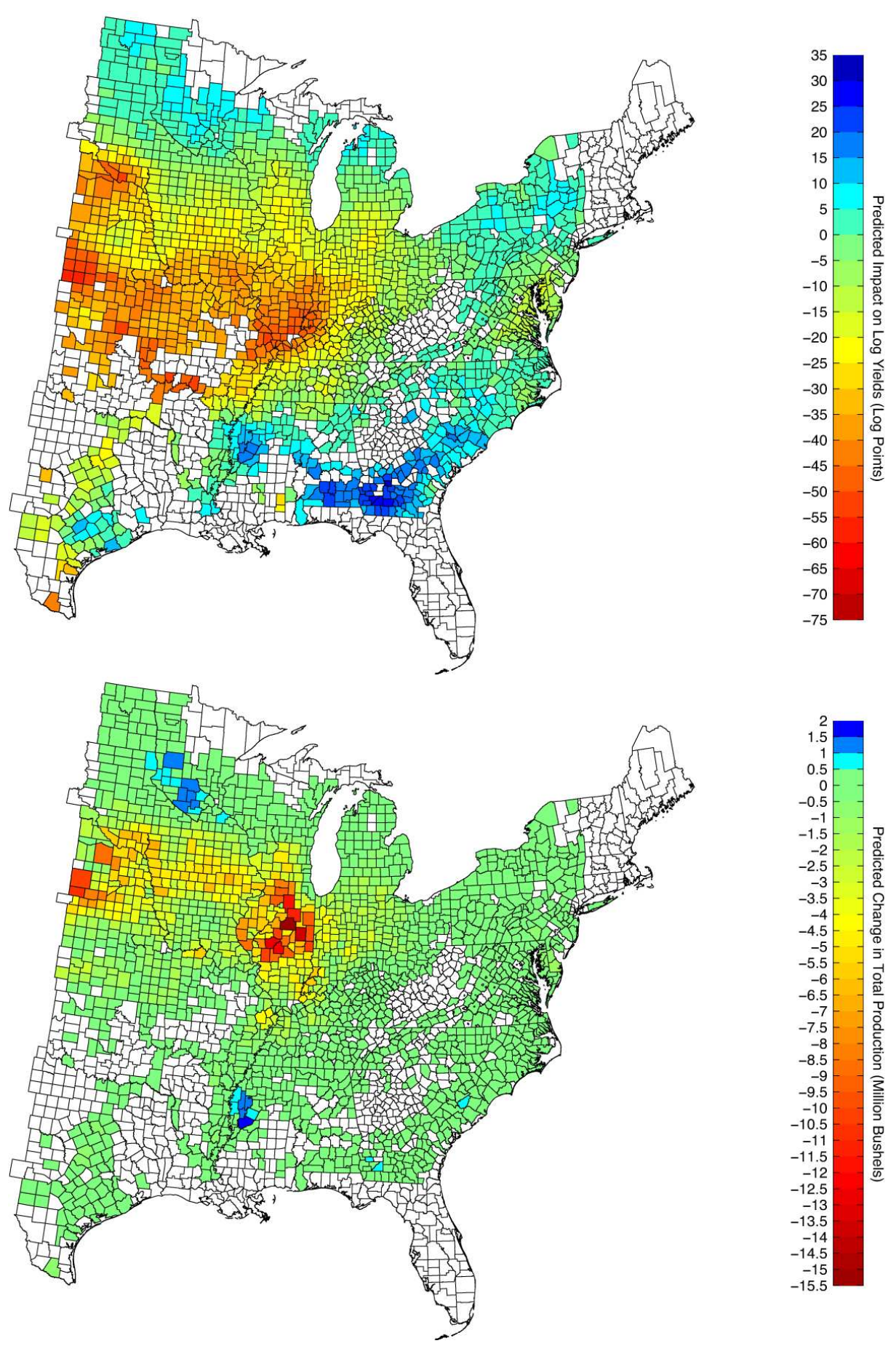

Notes: Predicted yield and production impacts in 2012 by county using the regression specification in column (1a) of Table 2. The top panel shows changes in predicted yields in log points, while the bottom shows predicted changes in total production (using the average area of 2009-2011 as growing area). Total predicted production in the shown counties was 11.4 billion bushels, and the production shortfall was 1.7 billion bushels, or $15 \%$. 
Figure 8: Effect of Degree Days above 29C as it Varies Over the Growing Season
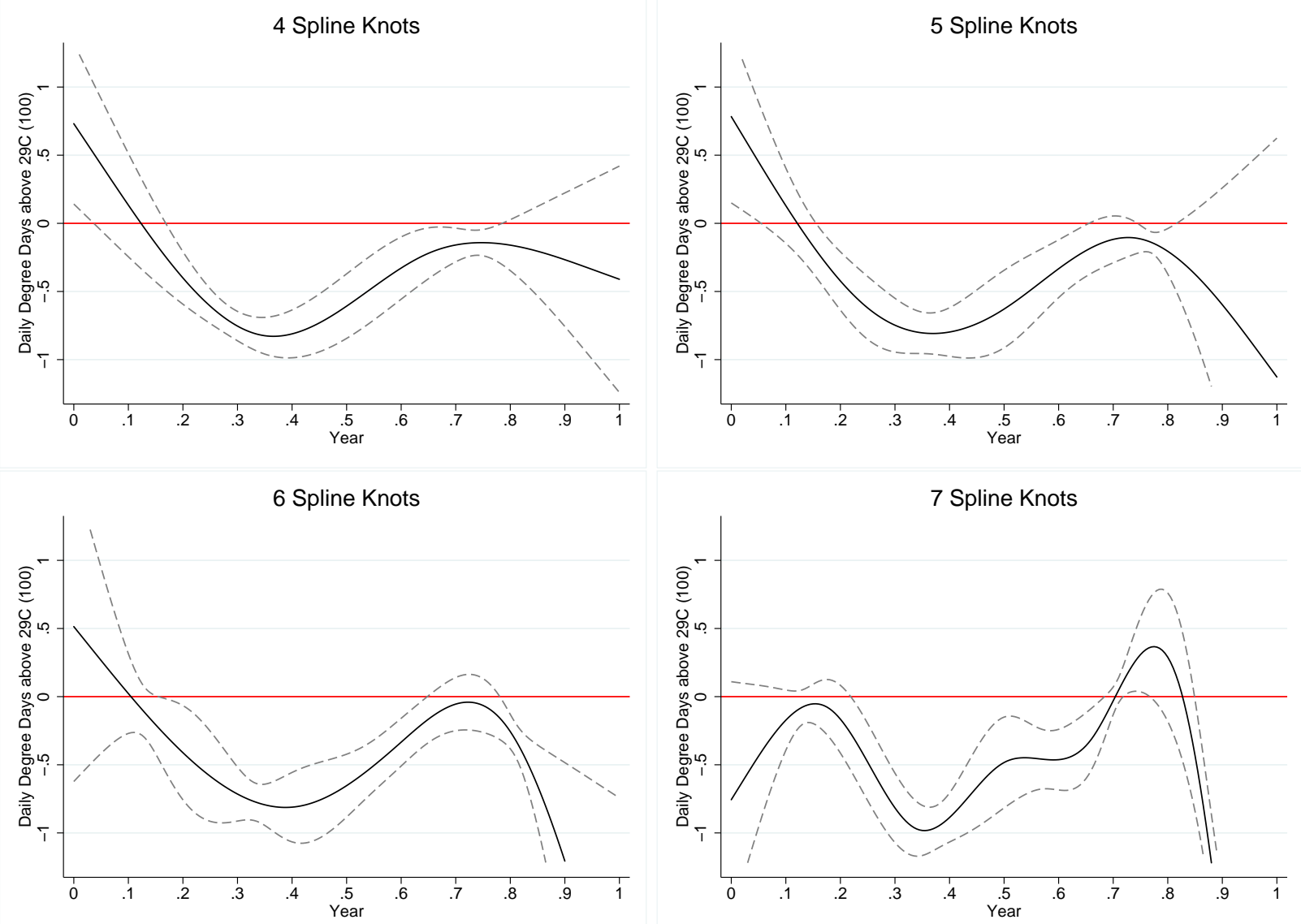

Notes: Panels show the marginal effect of 100 degree days above 29C. A reference model that fixes the effect to be the same across the growing season gave an estimate of -0.59 in column (1) of Table 3 . 
Figure 9: Predicted Yields in 2012 Using Time Varying Coefficients
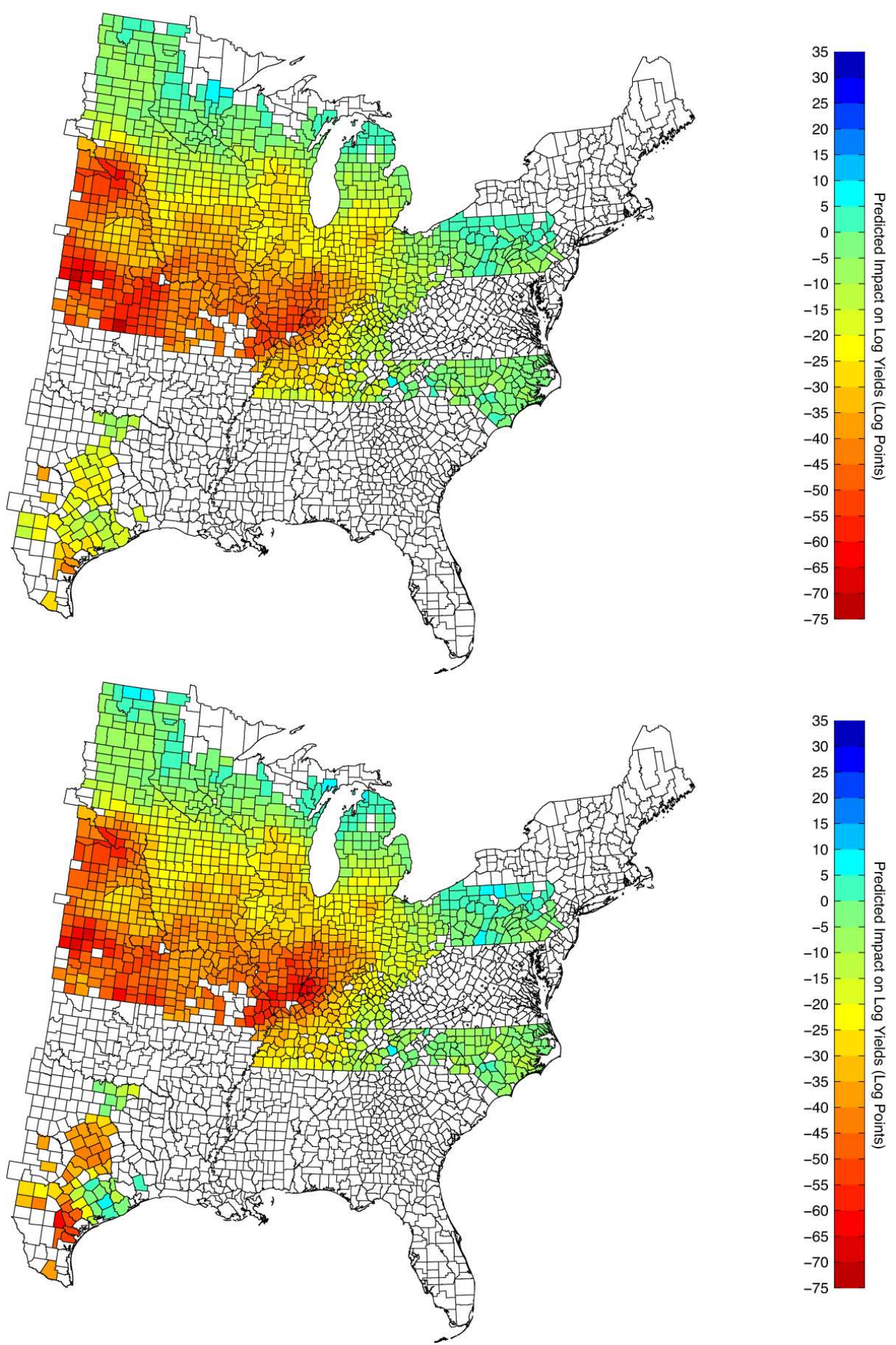

Notes: Both panels show changes in predicted yields in log points. The top panel uses the regression specification in column (2b) of Table 3, while the bottom panel uses the specification in column (6) of Table 4. 
Table 1: Descriptive Statistics of County Samples

\begin{tabular}{lcccccc}
\hline \hline & \multicolumn{2}{c}{ Production } & \multicolumn{2}{c}{ Area Harvested } & \multicolumn{2}{c}{ Yield } \\
& $\begin{array}{c}\text { Billion } \\
\text { Bushels }\end{array}$ & $\begin{array}{c}\text { Percent of } \\
\text { US Total }\end{array}$ & $\begin{array}{c}\text { Million } \\
\text { Acres }\end{array}$ & $\begin{array}{c}\text { Percent of } \\
\text { US Total }\end{array}$ & $\begin{array}{c}\text { Bushel } \\
\text { per Acre }\end{array}$ & $\begin{array}{c}\text { Percent of } \\
\text { US Total }\end{array}$ \\
\hline US Total & 12.63 & & 81.64 & & 154.73 & \\
Eastern Counties & 11.44 & $90.53 \%$ & 73.28 & $89.76 \%$ & 156.07 & $100.87 \%$ \\
Planting Dates & 10.95 & $86.72 \%$ & 69.49 & $85.12 \%$ & 157.63 & $101.87 \%$ \\
\hline \hline
\end{tabular}

Notes: Table summarizes the subsets of counties used in this study. Data is given for the most recent three years 2009-2011. Eastern counties are all counties east of the 100 degree meridian except Florida. Counties with planting dates are all eastern counties where state-level planting dates are available. 
Table 2: The Effect of Weather on Maize Yields using a Fixed Growing Season March-August

\begin{tabular}{lcccccc}
\hline \hline & $(1 \mathrm{a})$ & $(1 \mathrm{~b})$ & $(1 \mathrm{c})$ & $(2 \mathrm{a})$ & $(2 \mathrm{~b})$ & $(2 \mathrm{c})$ \\
\hline Thousand Degree Days $10-29^{\circ} \mathrm{C}$ & $0.314^{* * *}$ & $0.301^{* * *}$ & $0.303^{* * *}$ & $0.346^{* * *}$ & $0.343^{* * *}$ & $0.361^{* * *}$ \\
& $(0.068)$ & $(0.066)$ & $(0.063)$ & $(0.082)$ & $(0.079)$ & $(0.074)$ \\
Hundred Degree Days Above $29^{\circ} \mathrm{C}$ & $-0.622^{* * *}$ & $-0.616^{* * *}$ & $-0.625^{* * *}$ & $-0.580^{* * *}$ & $-0.583^{* * *}$ & $-0.584^{* * *}$ \\
& $(0.068)$ & $(0.066)$ & $(0.065)$ & $(0.069)$ & $(0.068)$ & $(0.067)$ \\
& $1.028^{* * *}$ & $1.016^{* * *}$ & $1.029^{* * *}$ & $1.092^{* * *}$ & $1.061^{* * *}$ & $1.095^{* * *}$ \\
Precipitation (m) & $(0.212)$ & $(0.208)$ & $(0.198)$ & $(0.217)$ & $(0.216)$ & $(0.209)$ \\
& $-0.806^{* * *}$ & $-0.800^{* * *}$ & $-0.818^{* * *}$ & $-0.807^{* * *}$ & $-0.787^{* * *}$ & $-0.814^{* * *}$ \\
Precipitation (m) Squared & $(0.165)$ & $(0.160)$ & $(0.153)$ & $(0.163)$ & $(0.161)$ & $(0.156)$ \\
& 0.7734 & 0.7784 & 0.7810 & 0.7920 & 0.7955 & 0.7972 \\
$\mathrm{R}^{2}$ & 115205 & 115205 & 115205 & 115205 & 115205 & 115205 \\
Observations & 2276 & 2276 & 2276 & 2276 & 2276 & 2276 \\
Counties & 3 & 4 & 5 & 3 & 4 & 5 \\
Spline Knots & No & No & No & Yes & Yes & Yes \\
Year Fixed Effects & & & & & &
\end{tabular}

Notes: Table regresses log maize yields for counties east of the 100 degree meridian (except Florida) in the year 1950-2011 on four weather variables as well as time controls. Columns (a), (b), and (c) include state-specific restricted cubic splines in time with 3, 4, and 5 knots, respectively, as time controls. The last three columns additionally include year fixed effects. Errors are clustered at the state level. Stars indicate significance levels: ${ }^{* *}: 1 \%{ }^{* *}: 5 \%{ }^{*}: 10 \%$. 
Table 3: The Effect of Weather on Maize Yields using Time-Varying Growing Seasons

\begin{tabular}{|c|c|c|c|c|c|}
\hline & $(1)$ & $(2 \mathrm{a})$ & $(2 \mathrm{~b})$ & $(2 \mathrm{c})$ & $\overline{(2 \mathrm{~d})}$ \\
\hline \multicolumn{6}{|c|}{ Panel A: Time Invariant Variables } \\
\hline Thousand Degree Days $10-29^{\circ} \mathrm{C}$ & $\begin{array}{c}0.333^{* * *} \\
(0.091)\end{array}$ & $\begin{array}{c}0.322^{* * *} \\
(0.087)\end{array}$ & $\begin{array}{c}0.320^{* * *} \\
(0.085)\end{array}$ & $\begin{array}{c}0.317^{* * *} \\
(0.086)\end{array}$ & $\begin{array}{c}0.322^{\text {*** }} \\
(0.083)\end{array}$ \\
\hline Hundred Degree Days Above $29^{\circ} \mathrm{C}$ & $\begin{array}{c}-0.591^{* * *} \\
(0.086)\end{array}$ & & & & \\
\hline Precipitation (m) & $\begin{array}{c}0.649^{* * *} \\
(0.211)\end{array}$ & $\begin{array}{l}0.622^{* *} \\
(0.217)\end{array}$ & $\begin{array}{l}0.608^{* *} \\
(0.230)\end{array}$ & $\begin{array}{c}0.589^{* *} \\
(0.216)\end{array}$ & $\begin{array}{c}0.648^{* * *} \\
(0.222)\end{array}$ \\
\hline Precipitation (m) Squared & $\begin{array}{c}-0.439^{* *} \\
(0.166)\end{array}$ & $\begin{array}{c}-0.392^{* *} \\
(0.166)\end{array}$ & $\begin{array}{c}-0.384^{* *} \\
(0.173)\end{array}$ & $\begin{array}{r}-0.373^{* *} \\
(0.166)\end{array}$ & $\begin{array}{c}-0.409^{* *} \\
(0.170)\end{array}$ \\
\hline \multicolumn{6}{|c|}{ Panel B: Joint Significane of Time Varying Variable } \\
\hline$F_{\text {Degree Days Above } 29^{\circ} \mathrm{C}}$ & & 80.45 & 70.54 & 64.45 & 51.68 \\
\hline$p_{\text {Degree Days Above } 29^{\circ} \mathrm{C}}$ & & $1.28 \mathrm{e}-10$ & $9.49 \mathrm{e}-11$ & $7.44 \mathrm{e}-11$ & $2.24 \mathrm{e}-10$ \\
\hline \multicolumn{6}{|c|}{ Panel C: Impact of 2012 Weather Outcome } \\
\hline Total Production Impact (\%) & -19.49 & -23.26 & -23.20 & -23.29 & -24.99 \\
\hline $\mathrm{R}^{2}$ & 0.5151 & 0.5366 & 0.5364 & 0.5369 & 0.5422 \\
\hline Observations & 43249 & 43249 & 43249 & 43249 & 43249 \\
\hline Counties & 1659 & 1659 & 1659 & 1659 & 1659 \\
\hline Spline Knots (Time Varying Var.) & & 4 & 5 & 6 & 7 \\
\hline
\end{tabular}

Notes: Table regresses log maize yields for counties east of the 100 degree where state-level plating dates are available in 1979-2011. Counties are shown in Figure 5. Column (1) uses the same specification as column (1a) in Table 2 except that it only uses counties and years for which planting dates are available and averages the weather variables over the actual growing season (instead of March-August). The remaining columns (2a)-(2d) allow the effect of degree days above $29^{\circ} \mathrm{C}$ to vary over the growing season. Columns differ by the number of spline knots used in the estimation of the seasonality, varying from 4 to 7 knots. The spline polynomials are shown in Figure 8. Panel B of the Table gives the F-statistics as well as the p-value for the joint significance of the time-varying components (not including the constant marginal effect). Panel $\mathrm{C}$ gives the predicted production shortfall from the 2012 weather outcomes. Errors are clustered at the state level. Stars indicate significance levels: ${ }^{* *}: 1 \% ;{ }^{* *}: 5 \%{ }^{*}: 10 \%$. 
Table 4: The Effect of Weather on Maize Yields using Time-Varying Growing Seasons and Precipitation Interactions

\begin{tabular}{|c|c|c|c|c|c|c|}
\hline & $(1)$ & $(2)$ & $(3)$ & $(4)$ & $(5)$ & 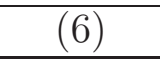 \\
\hline \multicolumn{7}{|c|}{ Panel A: Time Invariant Variables } \\
\hline Thousand Degree Days $10-29^{\circ} \mathrm{C}$ & $\begin{array}{c}0.333^{* * *} \\
(0.091)\end{array}$ & $\begin{array}{c}0.354^{* * *} \\
(0.075)\end{array}$ & $\begin{array}{c}0.334^{* * *} \\
(0.074)\end{array}$ & $\begin{array}{c}0.336^{* * *} \\
(0.072)\end{array}$ & $\begin{array}{c}0.313^{* * *} \\
(0.074)\end{array}$ & \\
\hline Hundred Degree Days Above $29^{\circ} \mathrm{C}$ & $\begin{array}{c}-0.591^{* * *} \\
(0.086)\end{array}$ & $\begin{array}{c}-0.562^{* * *} \\
(0.107)\end{array}$ & & & & \\
\hline DDays Above $29^{\circ} \mathrm{C}$ X Precipitation & & $\begin{array}{l}-32.434 \\
(31.588)\end{array}$ & $\begin{array}{l}-19.556 \\
(25.569)\end{array}$ & & & \\
\hline Precipitation $(\mathrm{m})$ & $\begin{array}{c}0.649^{* * *} \\
(0.211)\end{array}$ & $\begin{array}{c}0.708^{* * *} \\
(0.207)\end{array}$ & $\begin{array}{l}0.650^{* *} \\
(0.231)\end{array}$ & $\begin{array}{l}0.654^{* *} \\
(0.237)\end{array}$ & & \\
\hline Precipitation (m) Squared & $\begin{array}{c}-0.439^{* *} \\
(0.166)\end{array}$ & $\begin{array}{c}-0.473^{* * *} \\
(0.160)\end{array}$ & $\begin{array}{c}-0.409^{* *} \\
(0.170)\end{array}$ & $\begin{array}{c}-0.415^{* *} \\
(0.173)\end{array}$ & & \\
\hline \multicolumn{7}{|c|}{ Panel B: Joint Significane of Time Varying Variable } \\
\hline$p_{\text {Degree Days Above } 29^{\circ} \mathrm{C}}$ & & & $7.88 \mathrm{e}-10$ & $4.90 \mathrm{e}-09$ & $2.20 \mathrm{e}-07$ & $4.00 \mathrm{e}-09$ \\
\hline$p_{\text {Degree Days Above } 29^{\circ} \mathrm{C} \text { X Precipitation }}$ & & & & .0000632 & .00216 & .0158 \\
\hline$p_{\text {Precipitation }}$ & & & & & .00454 & .00429 \\
\hline$p_{\text {Precipitation Squared }}$ & & & & & .000852 & .00187 \\
\hline$p_{\text {Degree Days } 10-29^{\circ} \mathrm{C}}$ & & & & & & .0341 \\
\hline \multicolumn{7}{|c|}{ Panel C: Impact of 2012 Weather Outcome } \\
\hline Total Production Impact (\%) & -19.49 & -19.37 & -23.04 & -22.80 & -24.05 & -24.23 \\
\hline$\overline{\mathrm{R}^{2}}$ & 0.5151 & 0.5167 & 0.5370 & 0.5407 & 0.5524 & 0.5540 \\
\hline Observations & 43249 & 43249 & 43249 & 43249 & 43249 & 43249 \\
\hline Counties & 1659 & 1659 & 1659 & 1659 & 1659 & 1659 \\
\hline Spline Knots (Time Varying Var.) & & & 5 & 5 & 5 & 5 \\
\hline
\end{tabular}

Notes: Table regresses log maize yields for counties east of the 100 degree where state-level plating dates are available in 1979-2011. Counties are shown in Figure 5. Column (1) is the same as column (1) in Table 3. Column (2) adds an interaction term between daily extreme heat and precipitation. Column (3) allows the effect of extreme heat to vary over the growing season (similar to column (2b) in Table 3). Column (4)-(6) allow the effect of other variables to vary over the season: respectively, the effect of the interaction between extreme heat and precipitation, the effect of precipitation and precipitation squared, and the effect of moderate degree days $10-29^{\circ} \mathrm{C}$. Panel $\mathrm{B}$ of the Table gives the p-values for the joint significance of the time-varying components (not including the constant marginal effect). Panel C gives the predicted production shortfall from the 2012 weather outcomes. Errors are clustered at the state level. Stars indicate significance levels: ${ }^{* * *}: 1 \% ;{ }^{* *}: 5 \% ;{ }^{*}: 10 \%$. 